\title{
Exploration and Practice of "Integration of Production and Education, Integration of Science and Education and Integration of Theory and Practice" in Medical Talent Training
} \author{
Jian Huang1, Liqing Li', Xiaoyan Xia ${ }^{1}$, Nan Chen ${ }^{1}$, Qianli Tang ${ }^{*}$, Xuebin Li $^{1 *}$ \\ ${ }^{1}$ Youjiang Medical University for Nationalities, Baise, China \\ ${ }^{2}$ College of Pharmaceutical Sciences, Southwest University, Chongqing, China \\ Email: *htmgx919@163.com, *yyfylxb126@126.com
}

Xianjiu Liao1, Zhifeng Fu², Zuliang Huang1, Zhenzhong Li1, Qiaodan Pan1, Li Qian1, Bo Ling1,

How to cite this paper: Liao, X. J., Fu, Z. F., Huang, Z. L., Li, Z. Z., Pan, Q. D., Qian, L., Ling, B., Huang, J., Li, L. Q., Xia, X. Y., Chen, N., Tang, Q. L., \& Li, X. B. (2021). Exploration and Practice of "Integration of Production and Education, Integration of Science and Education and Integration of Theory and Practice" in Medical Talent Training. Advances in Applied Sociology, $11,308-314$.

https://doi.org/10.4236/aasoci.2021.116028

Received: May 26, 2021

Accepted: June 18, 2021

Published: June 21, 2021

Copyright $\odot 2021$ by author(s) and Scientific Research Publishing Inc. This work is licensed under the Creative Commons Attribution International License (CC BY 4.0).

http://creativecommons.org/licenses/by/4.0/ (c) (i) Open Access

\begin{abstract}
Purpose: To build a medical talent training mode based on "integration of production and education, integration of science and education and integration of theory and practice". Solutions: The talent training mode based on "integration of production and education, integration of science and education and integration of theory and practice" is finally built by taking "integration of science and education, integration of production and education, integration of theory and practice" as the focus of improving the quality of talent training to strengthen deep cooperation between universities and industries of talent training and deepen school-enterprise cooperation, taking students' participation in scientific research as an effective form of education to strengthen the construction of practical teaching bases, and using the project-based teaching methods such as PAD Class and flipped classroom to promote the close combination of theoretical and practical teaching. Results: This model underlines students and cultivates their ability to find and solve problems in practice, and enhances their post competence and comprehensive professional ability. Conclusion: The education mode in medical talent training of "integration of production and education, integration of science and education, and integration of theory and practice" is an effective way to train high-quality application-oriented undergraduate talents to improve students' career planning ability and employment competitiveness.
\end{abstract}




\section{Keywords}

Integration of Production and Education, School-Enterprise Cooperation, Integration of Science and Education, Integration of Theory and Practice, Medical Talents

\section{Introduction}

China, as the second largest pharmaceutical market in the world since 2015 (Cui, 2019), has a great demand for medical talents every year. However, the disconnection between the theory and practice of pharmaceutical talents trained under the traditional mode makes the supply of pharmaceutical talents unable to meet the needs of the industry (Chen, Wang, Wang, Sun, \& Bu, 2021). "Emphasizing knowledge but innovation" is in vogue for some time in medical talent training, and it is also insufficient to guide college students' innovative thinking; with the teaching process of "emphasizing theory but practice" and insufficient experimental practice and practical training of professional curriculum, the students need a long time of retraining in $\mathrm{R} \& \mathrm{D}$ units or enterprises after graduation $(\mathrm{Xu}$, 2021).

The reform of talent training mode determines its quality. Aiming at the problem of traditional talent training mode that emphasizes theory but not practice, and emphasizes knowledge but not innovation, and aiming at the cultivation of students' strong practical ability and innovative ability, we have built a medical talent training mode combining "integration of production and education (Mo, 2021), integration of science and education (Xu, 2021), and integration of theory and practice (Zhang, 2020)" by establishing the educational concept of "integration of production and education, integration of science and education and integration of theory and practice" and exploring a new path of training highquality application-oriented talents (Qiao, 2021), to train characteristic application-oriented talents with practical ability, consciousness of innovation, humanistic accomplishment and research and development capabilities of Zhuang and Yao ethnic medicine, and provide excellent reserve forces for the economic development of local characteristic medicine.

\section{Integration of Science and Education Is the Core of Application-Oriented Medical Talent Training}

Talent training and scientific research are both the responsibilities and missions of universities, and the frontier issues and achievements of scientific research should be incorporated into the teaching process through the close integration of teaching and scientific research. Focusing on the discipline characteristics, a characteristic practical teaching platform with the core of "key discipline-key laboratory-characteristic research of Zhuang and Yao ethnic medicine" is estab- 
lished in Youjiang Medical College For Nationalities, highlighting the cultivation of students' practical ability, and forming the school-running pattern and characteristics of coordinated development of "modern medicine, Zhuang ethnic medicine and Yao ethnic medicine". Relying on key disciplines of National Administration of Traditional Chinese Medicine (Chinese chemistry, rehabilitation of Chinese medicine), Guangxi key disciplines (pharmaceutical chemistry), scientific research platforms such as Traditional Chinese Medicine Research Laboratory (Chinese Medicine Chemistry, TCM Immunology and Pharmacology Laboratory) of National Administration of Traditional Chinese Medicine and Guangxi Universities and Colleges Key Laboratory (Youjiang River Basin Characteristic Ethnic Medicine Research Key Laboratory), this project full carries out the characteristic research of Zhuang and Yao ethnic medicine, takes the tutorial system for undergraduates as the carrier, enables students to enter projects and research teams as soon as possible, introduces the latest scientific research achievements into talent training, and demonstrates the scientific research feedback as the teaching highlight, our students have won more than 50 awards in various competitions nationwide and in Guangxi. Among them, 1 special award, 2 first awards and 3 second awards which were won in the National College Students' Experimental Skills Competition; 4 awards were won in the Provincial Chemical Industry Competition. Through the tutorial system for undergraduates, students are guided to apply for national and provincial innovative projects for undergraduates, and participate in national and provincial skill competitions to enrich the training methods of innovative ability, thus solving the path problem of scientific research feedback teaching, and truly realizing the exploratory learning.

In addition, the concept of integration of science and education should run through the whole process of "theory-experiment-open experiment-College Students' Innovative Entrepreneurial Training Plan Program-graduation thesis". The scientific research problem-oriented cases should be applied in "theoretical teaching"; the results of scientific research projects participated by students should be incorporated into the "experimental" teaching materials to embody the concept of scientific research feedback teaching; the "open experiment" platform is provided to students to stimulate their interest in scientific research; the students are guided to apply for "college students' innovation program", enabling them to enter various research teams and participate in their projects as soon as possible; combined with scientific research trends, the students are guided to select the topics of "graduation thesis" to improve the quality.

\section{The Integration of Production and Education Is the Key to Medical Talent Training}

The reform of talent training mode determines its quality, and the integration of production and education and school-enterprise cooperation are the key points of medical talent training. The mode and connotation of medical talent training 
are more profound with its increased quality requirements, and the integration of production and education and school-enterprise cooperation have become the fundamental needs and guarantees of medical talent training. The school-enterprise "double-subject" joint education requires schools and enterprises to study and formulate talent training programs, timely incorporate new technologies into teaching contents, and strengthen the practical training of students. The schoolenterprise "double-subject" joint education can better articulate with the pharmaceutical industry, connect with the talent requirements of enterprises, and train medical talents meeting the needs of society and enterprises (Guo, Zhou, \& Liao, 2021). 1) School-enterprise cooperation of practice bases in and outside the school. The pharmaceutical industry is related to people's life safety, and drugrelated work and posts have higher requirements for professional talents, which require students to master more skills before they can be applied to practice. Therefore, the construction of practice base is particularly important. The practice base in the school should employ enterprise experts to guide the whole process from design to construction, and build the practice base consistent with the actual production by introducing the strength of enterprises. We have built GMP training center and simulated pharmacy based on the working environment of professional positions, so that students can practice in an environment close to future work and lay a good foundation for competent; the construction of off-campus practice base should be strengthened, and the training plan should be jointly assessed by schools and enterprises to strengthen the supervision and management of students' practice. 2) School-enterprise cooperation of experimental class of "integration of production and education". Industry experts and innovation and entrepreneurship elites from outside the university participate in the whole process of talent training of "training objective formulation-teaching plan revision-curriculum construction-innovation and entrepreneurship projects and competition guidance-talent quality evaluation", In recent 5 years, undergraduates have obtained 3 national projects funded by the Innovation and Entrepreneurship Training Program for College Students and 20 provincial projects (Pan, Huang, Yang, Huang, Xiao, \& Huang, 2018). Since 2019, Youjiang Medical College for Nationalities has cooperated with Guangxi Agricultural Vocational College and Dashenlin Pharmaceutical Group Co., Ltd. to develop the coordinated training of application-oriented undergraduate talents of the integration of production and education in Science of Chinese Pharmacology, and has enrolled two sessions of students at present. The three parties jointly determine the oriented training programs of talents, and teaching reform should be carried out through the construction of curriculum system, teaching staff, practice base, talent motivation and evaluation system, etc; the theory and training program of post professional elements should be intergrated into the teaching materials to design links conforming to the characteristics of students and professions, lay a solid foundation for seamless connection between schools and enterprises, and train high-quality practical medical talents for the society. 


\section{The Integration of Theory and Practice Is an Important Way to Train Application-Oriented Medical Talents}

In a narrow sense, "theory" and "practice" in this integration refer to the combination of the two to encourage students to learn with problems through real projects as teaching carrier; in a broad sense, "theory" and "practice" refer to the combination of school and society to enable students to expand their knowledge and cultivate skills (Wang, 2019). Traditional medicine teaching pays too much attention to the presentation of theoretical knowledge in teaching materials, neglecting necessary skills for practical medicine-related posts. There is a big gap between the teaching content and the knowledge and skills required by the actual post. And it is difficult for students to understand and master what they have learned due to the lack of perceptual knowledge of the working scene, gradually losing interest in learning. 1) Through the innovation of teaching methods, the project-based teaching and heuristic teaching methods are used in this project such as PAD Class and flipped classroom, taking students as the main body and combining teaching with practice, Since 2012, the teachers have presided over 6 provincial educational reform projects on the subject of PAD Class and flipped classroom; aiming at the important and difficult points of teaching, the online teaching platforms such as Duifene and Moso Teach are used to record and publish micro-courses to encourage students to learn with problems, cultivate their independent learning ability, and promote the close combination of theoretical and practical teaching. 2) Under the concept of "integration of theory and practice", this project also focuses on the development of "integration of theory and practice" ideological and political and excellent traditional cultural case resources in professional curriculum education. For example, in recent years, more than 50 scientific research achievements of traditional Chinese medicine have won national science and technology awards; Researcher Tu Youyou became the first scientist in China to win the Nobel Prize in Physiology or Medicine because of her discovery of artemisinin in treating malaria. And the enhancement of students' "humanitic education" by combining theory with professional practice. In the implementation of tutorial system for undergraduates, the role of instructors should be expressed in medical humanitic education to carry out the characteristic research of Zhuang and Yao ethnic medicine, explore the humanistic resources in traditional Chinese medicine culture, consciously cultivate students' quality of inheriting traditional Chinese medicine culture, and truly unify "cultivating talents" and "educating people". 3) In accordance with the schoolrunning concept of application-oriented undergraduate, the demand for talents should be mastered by investigating the pharmaceutical production enterprises, hospitals and other employers, and the theoretical teaching should be incorporated into practical courses by revising the teaching syllabus to improve students' ability to solve practical problems; the practice link in course should be launched to improve students' practical ability through comprehensive training; combined with the knowledge learned in the school, post practice and systematic 
internship in enterprises and institutions should be carried out to train highskilled talents needed for local social and economic development.

\section{Conclusion}

In the past five years, undergraduates have won 3 national and 20 provincial projects supported by College Students' Innovative Entrepreneurial Training Plan Program, and more than 50 awards in competitions nationwide and in Guangxi. Among them, 1 special award, 2 first awards and 3 second awards which were won in the National College Students' Experimental Skills Competition; 4 awards were won in the Provincial Chemical Industry Competition. Since 2012, the teachers have presided over 6 provincial educational reform projects on the subject of PAD Class and flipped classroom.

Youjiang Medical College for Nationalities has gained a stage achievement in application-oriented medical talent training with "integration of production and education", and the application-oriented undergraduate major of the integration of production and education in Science of Chinese Pharmacology has been established, which has promoted the transformation of students' knowledge into skills and improvement of post competence and enhanced their employment competitiveness. Under the concept of integration of science and education, the characteristic practical teaching platform with the core of "key discipline-key laboratory-characteristic research of Zhuang and Yao ethnic medicine" is relied on to train the innovative ability of students in practical application and improve their practical application ability by taking innovative training projects for college students as the carrier. Under the concept of integration of science and education, the project-based teaching and heuristic teaching methods such as PAD Class and flipped classroom are used to motivate the students; during the characteristic research of Zhuang and Yao ethnic medicine, we should cultivate students' quality of inheriting traditional Chinese medicine culture and unify "cultivating talents" and "educating people". The medical talent training mode of "integration of production and education, integration of science and education and integration of theory and practice" has important spreading value for developing the biomedicine and health industries in Guangxi and even the whole country.

\section{Fund Program}

Guangxi Higher Education Undergraduate Teaching Reform Project (2018JGA237, 2018JGZ132, 2019JGZ138); Youjiang Medical College for Nationalities "Fifth School-level Renowned Teachers" Fund; Innovation Project of Guangxi Postgraduate Education(Project No.: JGY2021214, JGY2020170); Construction project of case bank for professional degree postgraduate teaching in Youjiang Medical University for Nationalities (Project Name: Case Bank Construction of Surgery Teaching). 


\section{Conflicts of Interest}

The authors declare no conflicts of interest regarding the publication of this paper.

\section{References}

Chen, S., Wang, J., Wang, H. J., \& Sun, J. W., \& Bu, M. (2021). Exploration and Practice of the Teaching Mode of Science and Education Integration in the Cultivation of Pharmaceutical Talents. China Continuing Medical Education, 13, 9-12.

Cui, Z. F. (2019). Take Advantage of the Trend and Win the New Development of the Pharmaceutical Cold Chain. China Logistics \& Purchasing, No. 17, 20-21.

Guo, X. Y., Zhou, H. Y., \& Liao, H. (2021). Construction of "Double Subject and Deep Integration" Industrial College from the Perspective of Integration of Production and Education. Education and Vocation, No. 8, 62-65.

Mo, L. H. (2021). Research on Interactive Translation Mobile Teaching Mode under the Concept of Science and Education Integration-An Effective Way to Cultivate Innovative Thinking and Scientific Research Ability. Chinese University Science \& Technology, No. Z1, 90-93.

Pan, Q. D., Huang, Y. H., Yang, C. Y., Huang, S. F., Xiao, G., \& Huang, S. Y. (2018). The Implementation and Construction of Student Evaluation System for Research Type Tutors in Medical College for Nationalities. Research and Exploration in Laboratory, 37, 279-282.

Qiao, J. Y. (2021). The Exploration of Constructing a New Engineering Education System of "Four Integrations". Chinese Higher Education, No. 2, 4-6.

Wang, Z. T. (2019). Research on Pharmaceutical Teaching Reform Strategies for Pharmaceutical Specialty in Colleges. Health Vocational Education, 37, 36-37.

Xu, X. Z. (2021). Connotation, Mechanism and Path of Training Innovation and Entrepreneurship Talents in Universities and Colleges Driven by Integration of Production and Education. Education and Vocation, No. 9, 63-67.

Zhang, D. L. (2020). Improving the Quality of Personnel Training, and Realizing Three Integrations. China Higher Education Research, No. 3, 1-3. 